- can be taken quickly, cheaply and without disturbing the statues. Several dozen highquality photos of a soldier, taken from multiple perspectives, can provide a computer algorithm with enough data to determine where each image was taken from and create a 3D map in a few minutes. The model - a set of $x$, $y$ and $z$ coordinates - can be plotted against other models, analysed and even used to make a cast with a $3 \mathrm{D}$ printer.

In a pilot study published on 4 June, Bevan's team modelled the faces of 30 warriors and found that no two ears were identical - evidence that the army consists of individuals (A. Bevan et al. J. Archaeol. Sci. http://doi.org/s7v; 2014). The researchers compared ears because these are unique and may have been modelled on real people. But they plan to analyse other anatomical features to see whether the soldiers vary in ethnicity or bear the hallmarks of distinct craftsmen. Bevan stresses that the work is at an early stage.

Archaeologists and

"We can expect
to see entire
collections of
hundreds of
thousands of
objects digitally
available."
palaeontologists have used computer modelling for decades, to map digs with laser scanners or study bones with computed tomography (CT), for example. But proponents of computer vision argue that these technologies are costly and not made for routine use in the field.

"You're talking about having a camera versus having a $£ 30,000$ [US\$50,000] piece of kit ready," says Sarah Duffy, an archaeologist at the University of York, UK. When

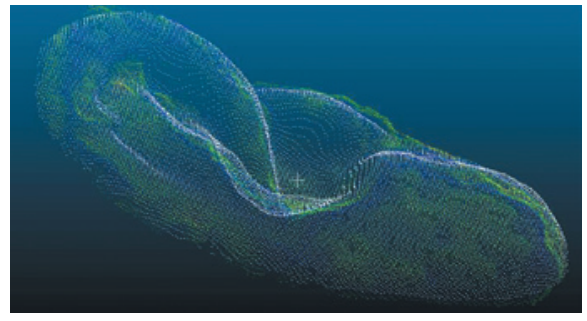

Superimposed 3D models (one in green, the other in white) reveal minute differences in ear shape.

900,000-year-old footprints were found on eastern England's Norfolk coast last year, she was part of a team that raced to photograph the scene and capture the footprints in $3 \mathrm{D}$. The resulting model revealed that they had been left by a human ancestor - the oldest such relics discovered outside Africa (N. Ashton et al. PLoS ONE http://doi.org/rd2; 2014). The prints had nearly vanished by the time the researchers lugged a laser scanner to the site a week later.

Benjamin Ducke at the German Archaeological Institute in Berlin agrees that the technology has the potential to preserve sites that are disappearing. Last October, he used a drone equipped with a video camera to create a 3D map of a large pre-Columbian settlement in Mexico in a couple of days. His team, called Project Archaeocopter, plans to analyse sites in Uzbekistan and at Pompeii in Italy. With an infrared camera mounted on a drone, the technology could map archaeological sites obscured by dense forests, he says.

Powerful computer-vision software is affordable and readily available, but advocates such as Heinrich Mallison, a palaeontologist at Berlin's Natural History Museum, see the technology as more than a time and money saver. "It means we can expect to see entire collections of hundreds of thousands of objects digitally available in a decade, so everybody can use these for research," he says. Ducke thinks that the technology has the potential to break the "interpretative monopoly" of scholars whose theories prevail because others lack access to particular artefacts or remains.

Jean-Jacques Hublin, a palaeoanthropologist at the Max Planck Institute for Evolutionary Anthropology in Leipzig, Germany, expects museums to limit the creation and distribution of such models in their collections, in the same way as some have done for CT scans. Museums worry about losing control over their collections, but Hublin thinks that demand among scientists will inevitably push more collections online. With computer-vision technology in mind, in May the European Union began accepting applications for a $€ 14$-million (\$19-million) fund to create 3D models of examples of Europe's cultural heritage.

But data theft is a worry, Mallison says. "I can go to a museum in Beijing, pull out my Canon, play tourist and do research on a high-resolution 3D model of their fossils." Academics might not risk the backlash of collecting data without permission, but replica sellers could pillage museum collections with computer-vision software, says Mallison. He thinks that international rules are needed to prevent this. Nevertheless, he predicts that it is only a matter of time before $3 \mathrm{D}$ models of museum collections are widely available. "The question is, do we see it in 5 years or 10 years or 15 years?" he says.

\title{
Tree hitched a ride to island
}

\section{Acacia analysis reveals globetrotting seed trekked 18,000 kilometres from Hawaii to Réunion.}

\section{BY EMMA MARRIS}

$\mathrm{I}$ $\mathrm{n}$ what is probably the farthest single dispersal event ever recorded, researchers have shown using genetic analysis that an acacia tree endemic to Réunion Island in the Indian Ocean is directly descended from a common Hawaiian tree known as the koa. In fact, these two trees on small specks of land on opposite sides of the globe turn out to be the same species.

The event is remarkable not just for the sheer distance covered - some 18,000 kilometres, almost the farthest apart that any two points on land can be - but that it occurred between two small islands. Koa seeds are unlikely to have floated to Réunion - they will not germinate after being soaked in seawater, and the trees grow in the mountains, not near the shore. The researchers, led by Johannes Le Roux, a molecular ecologist at Stellenbosch University in Matieland, South Africa, propose in a study published this week that a sea bird brought a seed from Hawaii to Réunion in its stomach or stuck to its feet in a one-off event some 1.4 million years ago (J. J. Le Roux et al. New Phytol. http://dx.doi. org/10.1111/nph.12900; 2014).

Le Roux notes that the physical similarities between the two trees, Acacia heterophylla from Réunion and Acacia koa from Hawaii, have been known for decades. "To me the most exciting thing is that we have solved this riddle," he says. "And how improbable is it?"

Le Roux and his team sequenced the DNA from 88 trees, including $A$. heterophylla, A. koa and a closely related acacia species from Australia, where the family originated. They found that all the acacias on Réunion share a genetic signature that is just one mutational step away from that of some Hawaiian koas. Using the slight differences between the trees' sequences, they developed a family tree, which clearly showed that all $A$. heterophylla are more closely related to one type of Hawaiian koa than some other types of koa are to each other.

To work out when the dispersal event took place, the team used a 'molecular clock'. This counts up genetic changes between populations 
$z$ and uses an estimated mutation rate to derive the date that populations first split. The team knew that the koa tree originally came from Australia, and that the earliest point at which I it could have become established on Hawaii was when Kauai, one of the older Hawaiian islands with the high elevations that koas prefer, formed 5.1 million years ago. Comparison of the Hawaiian koa and the trees on Réunion then showed that mutations that occurred in the subsequent 3.7 million years were present in both lineages. But mutations that occurred after that were found in either the Réunion trees or the Hawaiian trees, but not in both; this genetic divergence suggests that the dispersal event took place 1.4 million years ago.

Le Roux has ruled out the possibility of humans transferring the seed, because the molecular clock suggests that genetic changes began long before humans arrived in Réunion. "Despite its close genetic relatedness to koas from Hawaii, you see there is already diversification that is unique to Réunion," he says.

The startling finding is the latest in a string of improbable long-distance dispersal events that have been uncovered in the past 15 years or so. These include the proposed movement of New World (flat-nosed) monkeys on a raft from Africa to South America less than 50 million years ago, long after the two continents split; and the transfer of sundew carnivorous plants (Drosera species) from western Australia to Venezuela, probably by birds (see 'Far and wide'). Such findings have shaken up the field of biogeography, which concerns itself with why species are found where they are.

In the past, similar species found on different land masses were presumed to be the result of the continents slowly drifting apart, says Alan de Queiroz, an evolutionary biologist at the University of Nevada, Reno, and author of The Monkey's Voyage (Basic, 2014), a book about long-distance dispersal. And islands were thought to be largely dead ends when it came to species dispersal. "Things don't go from islands," he says, "or at least that was the general thought."

But the newly discovered long-distance events are changing that opinion, and

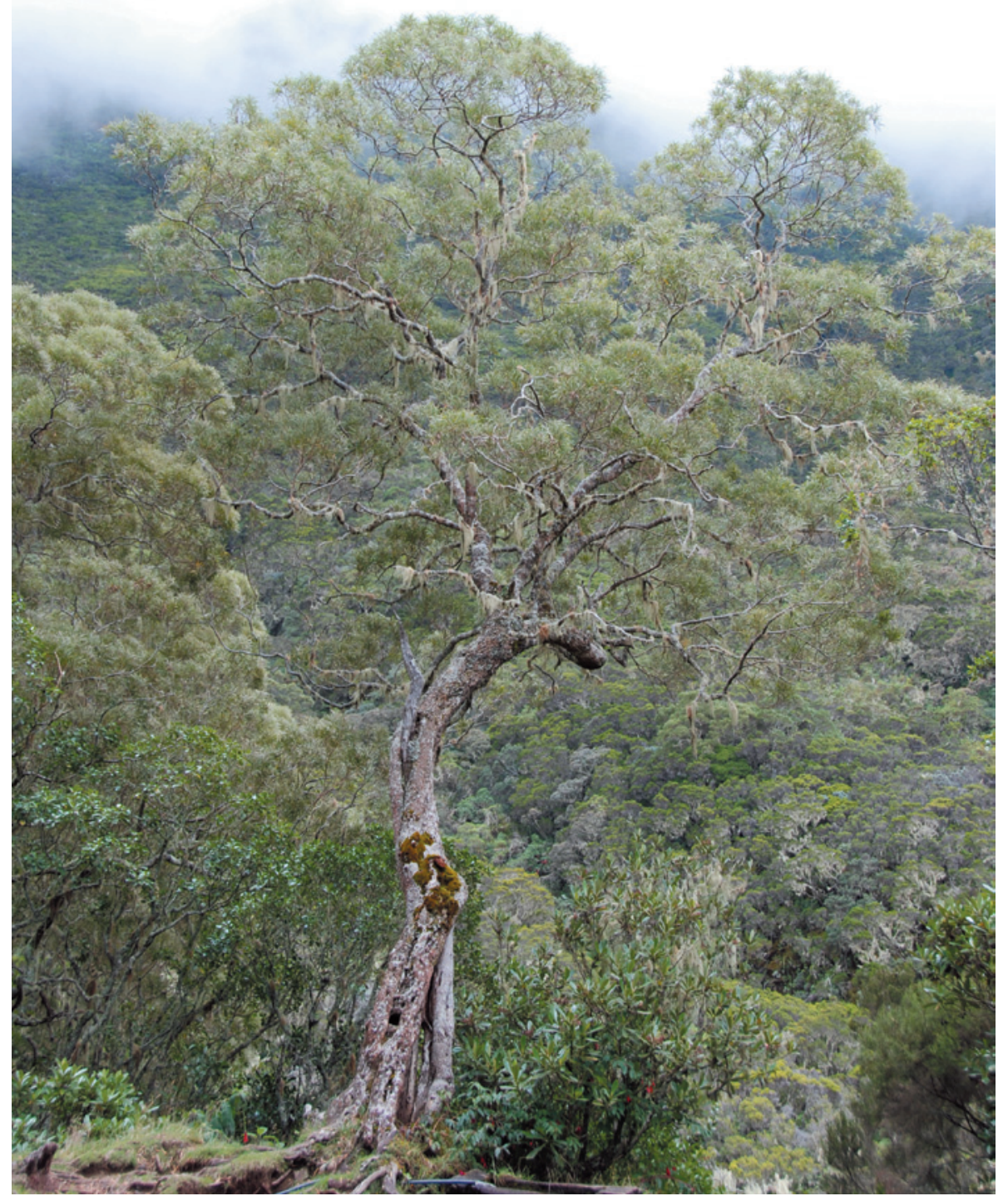

Ecologists have now shown that these acacia trees on Réunion are the same species as those on Hawaii.

biogeographers are increasingly stressing the role of improbable events and serendipity in shaping which species occur where. "The event [of the koa dispersal] is a giant fluke, but that's part of the message of a lot of recent biogeographic studies: that giant flukes happen," de Queiroz says.

As these accounts of long-distance dispersal accumulate, some ecologists say that the next challenge is to make predictive generalizations

about how often such events occur and which mechanisms (such as bird dispersal or rafting) are most important. "What we need to do is go beyond this accumulation of anecdotal evidence," says Ran Nathan, a movement ecologist at the Hebrew University of Jerusalem.

But the problem is that the rarity and accidental nature of such events may defy categorization. "There could be an argument that you get an endless list of very, very strange and

\section{FAR AND WIDE}

Several species are thought to have colonized areas far from their place of origin as a result of long-distance dispersal.

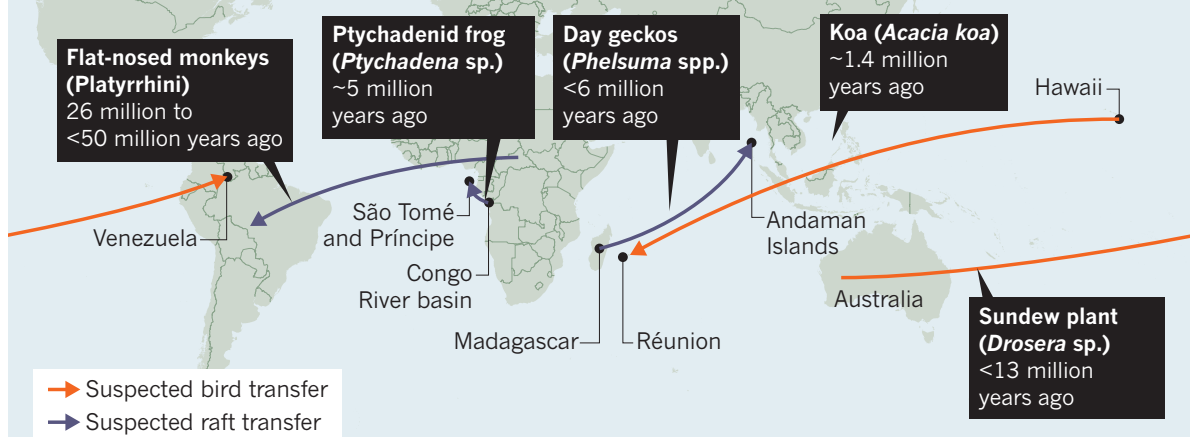

$\rightarrow$ Suspected raft transfer peculiar mechanisms," says Nathan. "There will be a long list, but there will be some mechanisms that are much more frequent."

Ecologist Jon Waters of the University of Otago in Dunedin, New Zealand, says that despite the potentially large role of longdistance dispersals in organizing global flora and fauna, such dispersals are not completely random or unpredictable. "As well as thinking about geographic proximity in making predictions about dispersal, there are numerous other factors to consider, such as oceanographic connectivity patterns, prevailing winds, storm tracks and even bird migrations," he says.

In other words, the distribution of some species may be the result of chance, time and luck - but there are still patterns. And science still has a part to play in elucidating them. 